\title{
Ground penetrating radar detection of subsnow slush on ice-covered lakes in interior Alaska
}

\author{
A. Gusmeroli ${ }^{1}$ and G. Grosse ${ }^{2}$ \\ ${ }^{1}$ International Arctic Research Center, University of Alaska Fairbanks, Fairbanks, Alaska, USA \\ ${ }^{2}$ Geophysical Institute, University of Alaska Fairbanks, Fairbanks, Alaska, USA
}

Correspondence to: A. Gusmeroli (alessio@iarc.uaf.edu)

Received: 19 June 2012 - Published in The Cryosphere Discuss.: 31 July 2012

Revised: 16 November 2012 - Accepted: 26 November 2012 - Published: 6 December 2012

\begin{abstract}
Lakes are abundant throughout the pan-Arctic region. For many of these lakes ice cover lasts for up to two thirds of the year. The frozen cover allows human access to these lakes, which are therefore used for many subsistence and recreational activities, including water harvesting, fishing, and skiing. Safe traveling condition onto lakes may be compromised, however, when, after significant snowfall, the weight of the snow acts on the ice and causes liquid water to spill through weak spots and overflow at the snow-ice interface. Since visual detection of subsnow slush is almost impossible our understanding on overflow processes is still very limited and geophysical methods that allow water and slush detection are desirable. In this study we demonstrate that a commercially available, lightweight $1 \mathrm{GHz}$, ground penetrating radar system can detect and map extent and intensity of overflow. The strength of radar reflections from wet snow-ice interfaces are at least twice as much in strength than returns from dry snow-ice interface. The presence of overflow also affects the quality of radar returns from the base of the lake ice. During dry conditions we were able to profile ice thickness of up to $1 \mathrm{~m}$, conversely, we did not retrieve any icewater returns in areas affected by overflow.
\end{abstract}

\section{Introduction}

Shallow lakes and ponds are abundant throughout the panArctic region. These water bodies can have various origins, including thermokarst, glacial, fluvial, deltaic or structural (Smith et al., 2007; Jones et al., 2011; Arp and Jones, 2009). The surfaces of these lakes typically start to freeze in the fall and remain solid and ice covered until the spring. The freezing rate, ice growth, and resulting ice thickness are strongly conditioned by the amount of snow that resides above (Adams and Roulet, 1980; Liston and Hall, 1995; Sturm and Liston, 2003). Once formed, lake ice is also affected by cracking and fracturing due to thermal expansion and shrinkage during the lake ice formation, and windcaused drift processes, often creating weak zones in the ice. Another process that adds weak zones in ice of thermokarst lakes is strong year-round methane emission from lake and taberal sediments, causing inclusion of large gas bubbles in the vertical ice column and in some cases the maintaining of methane emission hotspots that remain open water throughout much of the year (Walter et al., 2010). During the winter, ice-covered freshwater lakes in the sub-Arctic have a tangible societal role. Lakes are visited for fishing, harvesting water, and recreational activities such as camping, skidoo travels, skiing and dog mushing.

Travel, work and recreation on frozen freshwater bodies present some hazards. The higher hazards are at the beginning and at the end of the ice-covered season when ice is either not yet thick and stable enough (fall) or begins to be structurally damaged from increasing temperature (spring). Another significant hazard present during the entire winter is the occurrence of severe overflow events (Fig. 1a). After a significant snowfall, the weight of the new snowpack acts on the ice and causes water to spill above the ice through weak spots, such as cracks or methane hot-spots. After an overflow event, the base of the snowpack changes from dry snow to water-flooded snow (slush). In severe events (e.g., complete flooding of the snowpack, Fig. 1a) hazardous conditions are recognizable; in less severe, still hazardous cases (e.g., basal flooding, Fig. $1 \mathrm{~b}$ and $\mathrm{c}$ ), the direct visual detection of the 

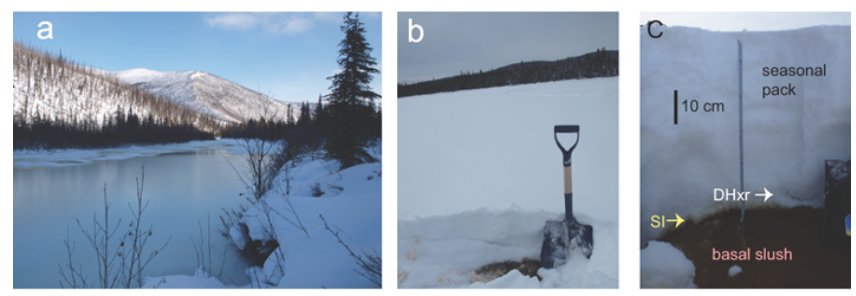

Fig. 1. (a) one of the most severe overflow event we have noticed in the winter 2012 on freshwater bodies in the vicinity of Fairbanks. The photo shows the West Fork of the Chena river on 11 March 2012. Safe access to the river is impeded by a vast amount of water which entirely flooded the snowpack. The photo pictures an area in which overflow is clearly visible to human eye. In some areas (also visible in the picture) overflow water did not flood the snowpack as a whole; in this case the hazard is still high but is not as visible. The cross section of the river is approximately $20 \mathrm{~m}$. (b) The overflow event at Ace Lake on 15 March 2012. Liquid water only flooded the basal part of the snowpack. A detail of the wet snow base is provided in (c). Rounded depth hoar (RDH) and Snow-ice (SI) above the slush are visible.

presence of basal slush or liquid water beneath the snowpack is almost impossible, and the development of geophysical techniques for measuring snow and ice thickness and detecting subsnow water is desirable.

In this study, we employ a commercially available, portable, $1 \mathrm{GHz}$ Ground Penetrating Radar (GPR) to study the radar characteristics of ice-covered lakes affected by liquid overflow in the snowpack. While the use of GPR to measure snow and lake-ice thickness is well-known (Arcone et al., 1997), the detection of subsnow liquid overflow and slush using GPR has received little attention so far. We demonstrate that GPR is a powerful method to detect and map the presence of subsnow slush and the magnitude of overflow. This is because sub-snowpack water strongly affects the GPR signal. The GPR response to dry snow-ice interfaces was very different from the GPR response to wet snow-ice interface. During the dry case (no liquid overflow), the GPR signal was able to penetrate through the snow-ice interface and reflections from the base of the lake ice were successfully retrieved. Conversely, when the base of the snowpack was wet (extensive overflow), the signal was unable to penetrate to the base. Our findings indicate that it might be possible to develop routine mapping of overflow slush with groundbased, air-borne and space-based radar.

\section{Field area and methods}

GPR measurements were made in 2012 at 3 thermokarst lakes (Smith Lake, Ace Lake and Killarney Lake) in the Fairbanks area, interior Alaska. Surveys were made on 12 March (Smith Lake), 13 March (Ace Lake) and 21 March (Killarney Lake). The GPR system was a lightweight, commercially available PulseEkko Pro System with $1 \mathrm{GHz}$ antennas con- nected to it. A handheld Garmin GPS system was attached to the GPR to store the coordinates of the GPR profiles. The survey was operated in standard GPR reflection mode. The GPR system emits radar pulses which are reflected by the interface between the snow and the top of the lake ice. The second event recorded in these surveys is the reflection from the base of the lake ice. The travel time of these different reflections to the surface can be used to estimate snow and ice depth.

GPR is a powerful tool for non-destructively measuring snow and ice thickness in cold regions. Many authors have used GPR to characterize alpine (Marshall et al., 2005; Bradford et al., 2009a; Heilig et al., 2010), arctic (Holmgren et al., 1998), and on-glacier (Macguth et al., 2006) snowpack. Studies on freshwater ice have demonstrated that GPR can profile lake ice (Arcone et al., 1997) and river ice (Arcone and Delaney, 1987) thickness. The clarity, the spatial continuity and the very shallow position of shallow cryospheric targets typically results in reliable GPR depth estimates with minimal signal processing (e.g., Macguth et al., 2006; Gusmeroli et al., 2012). The only processing applied to the radar images presented here was the removal of the instrumental, low-frequency noise that is typical of GPR systems. This low frequency noise is known as "wow" in the radar literature, and the filter associated to it is called dewow.

The quantitative analysis of radar reflections required further processing. Such a processing workflow was very similar to one typically used for studies of attenuation of seismic signals in ice (e.g., Gusmeroli et al., 2010; Peters et al., 2012). The processing flow consisted of the following steps: (i) the travel-time of the reflections from the base of the snowpack were picked using a phase-follower algorithm; (ii) travel-time values were used to extract a $3 \mathrm{~ns}$ long $(\sim 3$ cycles) time-window that contained the waveforms of the snow-ice reflection; (iii) a Fast Fourier Transform algorithm was used to calculate the spectral amplitude of each waveform; (iv) the maximum value of the spectral amplitude was taken as a proxy of radar reflectivity and this value was corrected for geometric divergence.

In addition to GPR data, we collected data of snow thickness, slush thickness, ice thickness, and total water depth in several locations along the GPR profiles by digging snow pits and drilling and measuring ice holes.

\section{Results}

In the study, lakes snow thickness ranged from $30-70 \mathrm{~cm}$, ice thickness was $49-65 \mathrm{~cm}$, and water depth from 0-695 cm. A substantial late-season snowfall $(20-40 \mathrm{~cm}$ of new snow in two days) in the week before our surveys in early March 2012 strongly increased snow weight on the ice, causing overflows in various areas of many lakes. Slush thickness at Ace and Killarney Lake ranged from 2-22 cm and was highly variable within a lake area and between lakes. Figure 1c shows details of the snowpack at Ace Lake in case of overflow. 


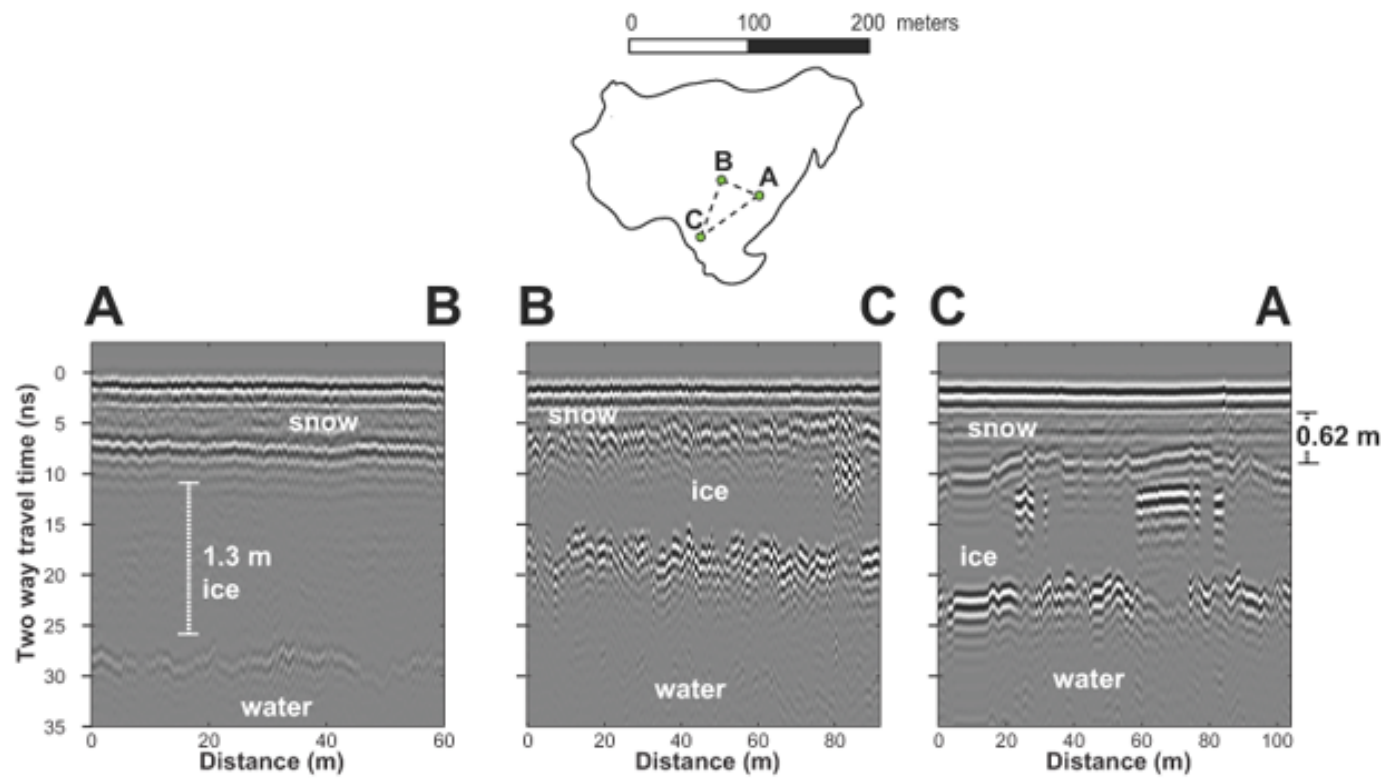

Fig. 2. $1 \mathrm{GHz}$ GPR profiles acquired at Smith Lake. No overflow water was noticed at the snow-ice interface. Bars indicating thicknesses in snow and ice were calculated using radar speed in snow of $0.21 \mathrm{~m} \mathrm{~ns}^{-1}$ ((AB); compacted snow); $0.25 \mathrm{~m} \mathrm{~ns}^{-1}$ ((BC), (CA); loose snow) and $0.168 \mathrm{~m} \mathrm{~ns}^{-1}$ in ice.

We identified two different GPR-snow-ice characteristics that were different between dry-based snowpack and wet-based snowpack.

\subsection{Dry snow-ice interface, no overflow}

At Smith Lake (Fig. 2), there was no sign of water at the base of the snowpack. The snow-ice interface was dry. The GPR profiles were purposely collected on three different types of snowpacks: (i) a well-compacted snowpack on an established ski trail (Profile AB, Fig. 2); (ii) a disturbed snowpack, in which a trail was established prior to GPR survey (Profile BC, Fig. 2); and (iii) a pristine snowpack in which the GPR was allowed to float on the fresh snow surface (Profile CA, Fig. 2c). Results in Fig. 2 are presented with GPR twoway travel times. Thickness bars, included for visualization, were derived by assuming radar wave speeds of 0.25 and $0.168 \mathrm{~m} \mathrm{~ns}^{-1}$ for snow and ice, respectively (Robin, 1975). These velocities are typically observed in snow-ice studies and are consistent with measurements obtained in the field.

From all three GPR profiles collected at Smith Lake we can distinguish two prominent reflectors (Fig. 2). The shallower reflector is the snow-ice interface. The deeper reflector is the ice-water or the ice-sediment interface. Results are very sensitive to the conditions of the snowpack. The clearest reflections are observable in the compacted snowpack (Fig. 2, $\mathrm{AB}$ ) and in the pristine snowpack (Fig. 2, CA). The clarity and the spatial continuity of the reflectors is less visible on the newly established snow trail, most likely because the GPR is towed over an irregular surface. The internal ice reflectors observable in BC and CA are caused by survey ca- bles lying on the snow (we conducted our GPR surveys at the same time with other geophysical investigations). To summarize, this $1 \mathrm{GHz}$ GPR survey in a dry snow-ice interface situation successfully retrieved reflections from the base of the lake ice.

\subsection{Wet snow-ice interface, overflow present}

At Ace and Killarney lakes, we noticed that liquid water was present beneath the snowpack (e.g., Fig. $1 \mathrm{~b}$ at Ace Lake). Both thermokarst lakes had a substantial number of methane emission hotspots of $10-30 \mathrm{~cm}$ in diameter that were only covered with a thin crust of ice and snow, while the other areas of both lakes were covered with ice ranging in thickness from $49-65 \mathrm{~cm}$. The overflow water was in the form of basal slush on 12-13 March and started to freeze subsequently. Granular snow-ice (flooded snow with refrozen liquid phase) with some degree of wetness was observed in the following days until late March. As the temperatures rose above freezing, snowmelt started, and it became impossible to distinguish whether the basal snow wetness was due to overflow or water percolation from surface melt.

At Ace Lake we undertook a variety of GPR profiles, including a line crossing the entire lake (Fig. 3) and a detailed study on the shores (Fig. 3). The long profile showed a surprising behavior: the reflections from the base of the lake ice were only detectable nearby the shore. Over the vast majority of the lake, the ice-water reflections were obscured by a high amplitude series of echoes from the wet snow-ice interface (Fig. 3). 
The detailed study on the shore revealed other interesting features of overflow slush (Fig. 3). The strength of the snow-ice echoes gradually increased when moving from dry snow-ice conditions into wet snow-ice conditions (Fig. 3). The strength of the ice-water echoes behaved oppositely. The snow depth on the shore of the lake was about twice the snow depth on the lake (Fig. 3).

Similar results were noticed at Killarney Lake (Fig. 4). The Killarney case study provides an excellent example for spatial variability of overflow slush. At Killarney (Fig. 4), we noticed spatial variability in the intensity of the snowice reflection (e.g., $30-40 \mathrm{~m}$ in the pattern $\mathrm{k} 1-\mathrm{k} 2 ; 20-30 \mathrm{~m}$ in the pattern $\mathrm{k} 2-\mathrm{k} 3$; and the general pattern $\mathrm{k} 3-\mathrm{k} 4)$. This is particularly clear when the reflection is studied in detail (Fig. 5). By using the spectral amplitude corrected for geometric spreading, we can quantify the intensity of the reflection (Fig. $5 \mathrm{a}$ for the radargram and $5 \mathrm{~b}$ for the intensity). The spectral amplitude is up to five times higher in regions affected by severe overflow: the presence of slush and the magnitude of subsnow overflow can therefore be detected using high frequency GPR.

Details on the spatial variability in basal-snow reflectivity observed at Killarney lake is shown in Fig. 6. On-lake slush distribution is heterogeneous (e.g., with different magnitudes of flooding). Spectral amplitudes, corrected for geometric spreading varied significantly across the profile (Fig. 6). Returns from zones of intense overflow can be up to 5 times stronger than regions with no overflow. From this map we can identify hotspots of high reflectivity that correspond to wet areas.

\section{Discussion}

\subsection{Slush on ice-covered lakes}

The process of overflow, snowpack flooding, slush and snowice formation is important for ice thickness growth in both lake and sea ice (Adophs, 1998; Leppäranta and Kosloff, 2000; Saloranta, 2000). Slush is a mixture of ice, water and air and its physical properties are rarely measured in the field. Adophs (1998) reported difficulties in measuring slush density and reasoned that his highest measured value of $700 \mathrm{~kg} \mathrm{~m}^{-3}$ represented only the lower limit of a range that can extend up to $960 \mathrm{~kg} \mathrm{~m}^{-3}$ in case of full saturation with no air inclusions. Measurements of snow-ice density from lakes suggest air content values of 4-10\% (Saloranta, 2000; Leppäranta and Kosloff, 2000). Water-content values of the slush mixture are thought to be 40-60\% (Saloranta, 2000; Leppäranta and Kosloff, 2000). Slush forming from overflow on floating ice sheets is therefore in the funicular regime (water content $>15 \%$ ) and is different to the terrestrial slush in the pendular regime (water content $<15 \%$ ) that other radar studies have considered (e.g., Mitterer et al., 2011).

To understand this better, we undertook a simple modeling exercise. Specifically we aimed to provide a first order estimate of the volumetric fraction of water within the basal snow $\left(\theta_{\mathrm{w}}\right)$. We do this by generating a synthetic GPR dataset.

The response of the model will then be compared to our data to provide a quantification of $\theta_{\mathrm{w}}$. Our modeling exercise is very similar to the one applied recently by Bradford et al. (2009b); in their study Bradford et al. (2009b) generate synthetic GPR data in order to assess the usefulness of basal-snow reflectivity to detect oil under snow on the sea ice. They noticed that 2-cm-thick oil film trapped between snow and sea ice could be detected based on a $51 \%$ decrease in reflection strength.

We simulated the GPR response using the free-source modeling package MATGPR (http://users.uoa.gr/ atzanis/ matgpr/matgpr.html). The model runs in 2-D, the antennas are simulated as point source and is based on the FDTD (finite difference time domain) treatment of Maxwell's equations (Irving and Knight, 2006; Tzanis, 2006) and only requires model-geometry and dielectric permittivity $(\varepsilon$, Table 1) as input. We simulate GPR traces with different scenarios of overflow (Details in Table 1 and Fig. 7). The effect that water content has on dielectric permittivities was simulated by considering slush as a 3 phase dielectric medium composed by snow, air and water (Table 1). The dielectric permittivity of the slush $\varepsilon_{\mathrm{sl}}$ can be estimated with a three phase mixing model (e.g., Perla, 1991; Roth et al., 1990; Mitterer et al., 2011):

$\varepsilon_{\mathrm{s} l}=\theta_{\mathrm{w}} \varepsilon_{\mathrm{w}}+\left(1-\theta_{\mathrm{w}}-\theta_{\mathrm{a}}\right) \varepsilon_{\mathrm{i}}+\left(\theta_{\mathrm{a}}\right) \varepsilon_{\mathrm{a}}$,

where $\theta_{\mathrm{w}}$ is the volume fraction of water, $\epsilon_{\mathrm{i}, \mathrm{a}, \mathrm{w}}$ are the dielectric properties for the three constituents of the mixture (ice "i", air "a" and water "w") and $\theta_{\mathrm{a}}$ is the air content of the slush

Figures 7 and 8 show the results of the simulation. As noticed from the field data, the amplitude of the reflections from the base of the snowpack changes according to the properties of the basal material. Amplitude is lowest for a dry snowice interface (orange star in Fig. 7a, a1) and dramatically increases with adding a slush-layer to the model (Fig. 7b, b1) and increasing percentages of water in the slush (Fig. $7 \mathrm{c}$ to e). When $\theta_{\mathrm{w}}<10 \%$, the base of the slush layer is recognizable in the radar trace (green stars in Fig. $6 \mathrm{~g}$ and h). $\theta_{\mathrm{w}}>10$ are necessary to attenuate the reflections from the base of the slush layer and from the base of the lake-ice. A close look at the frequency spectrum from all the waveforms indicated with a orange star in Fig. 7 is shown in Fig. 8. Here the amplitude of the dry case (Fig. 6a, a1) being generated in a thicker snowpack was corrected for geometric spreading). Returns from the two cases with $\theta_{\mathrm{w}}>30 \%$ (Fig. 7 curves e and d) are stronger than any other cases.

The behavior of the modeled ice-water reflection is also consistent with what we have observed in the field data (Figs. 5, 6, 7, 8). Ice-water returns are stronger in the case of no overflow. The presence of overflow changes the dielectric properties of snow, greatly attenuates the radar energy and degenerate the quality of the ice-water returns. From our 


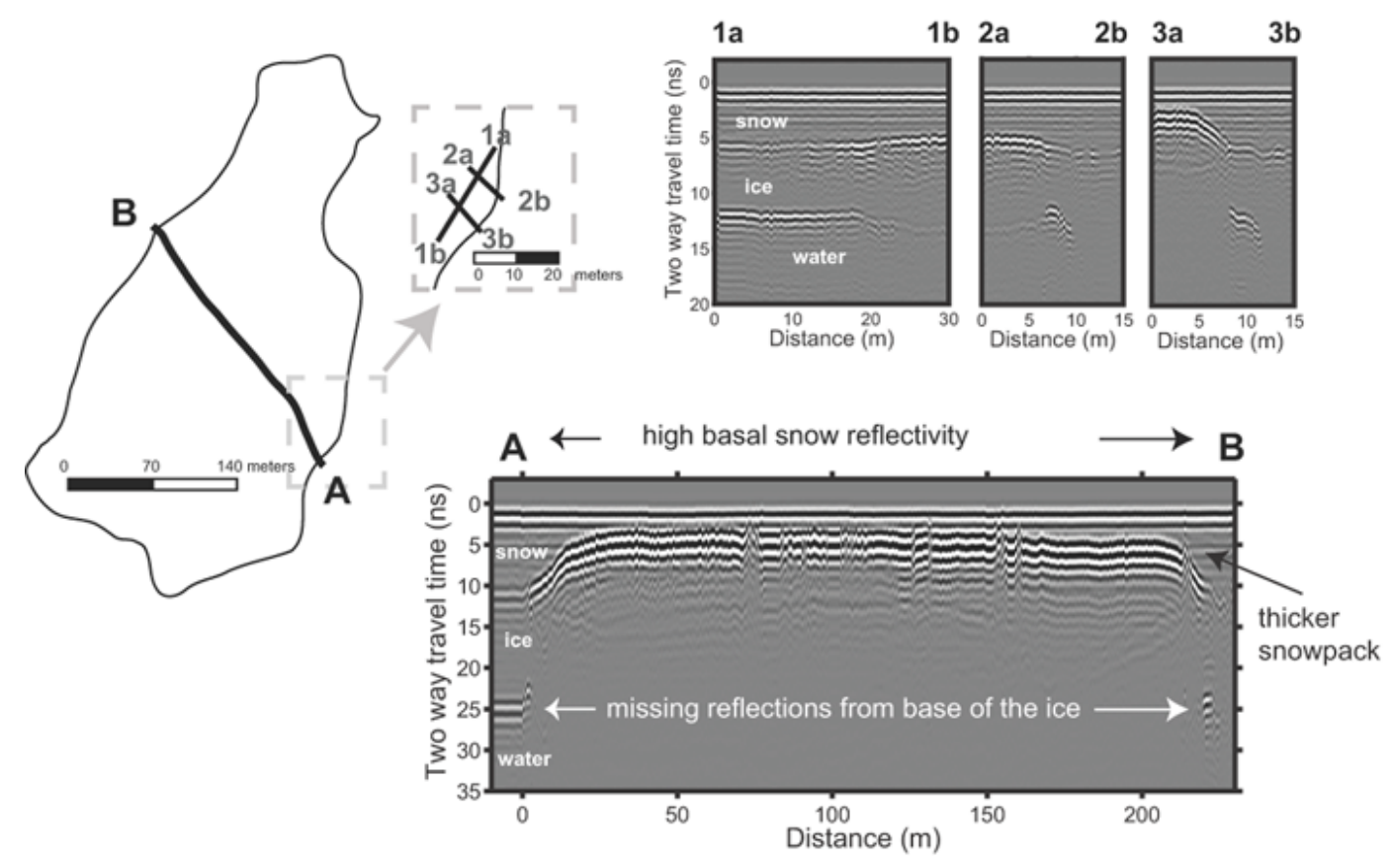

Fig. 3. $1 \mathrm{GHz}$ GPR profiles acquired at Ace Lake. Extensive overflow water was noticed at the snow-ice interface.
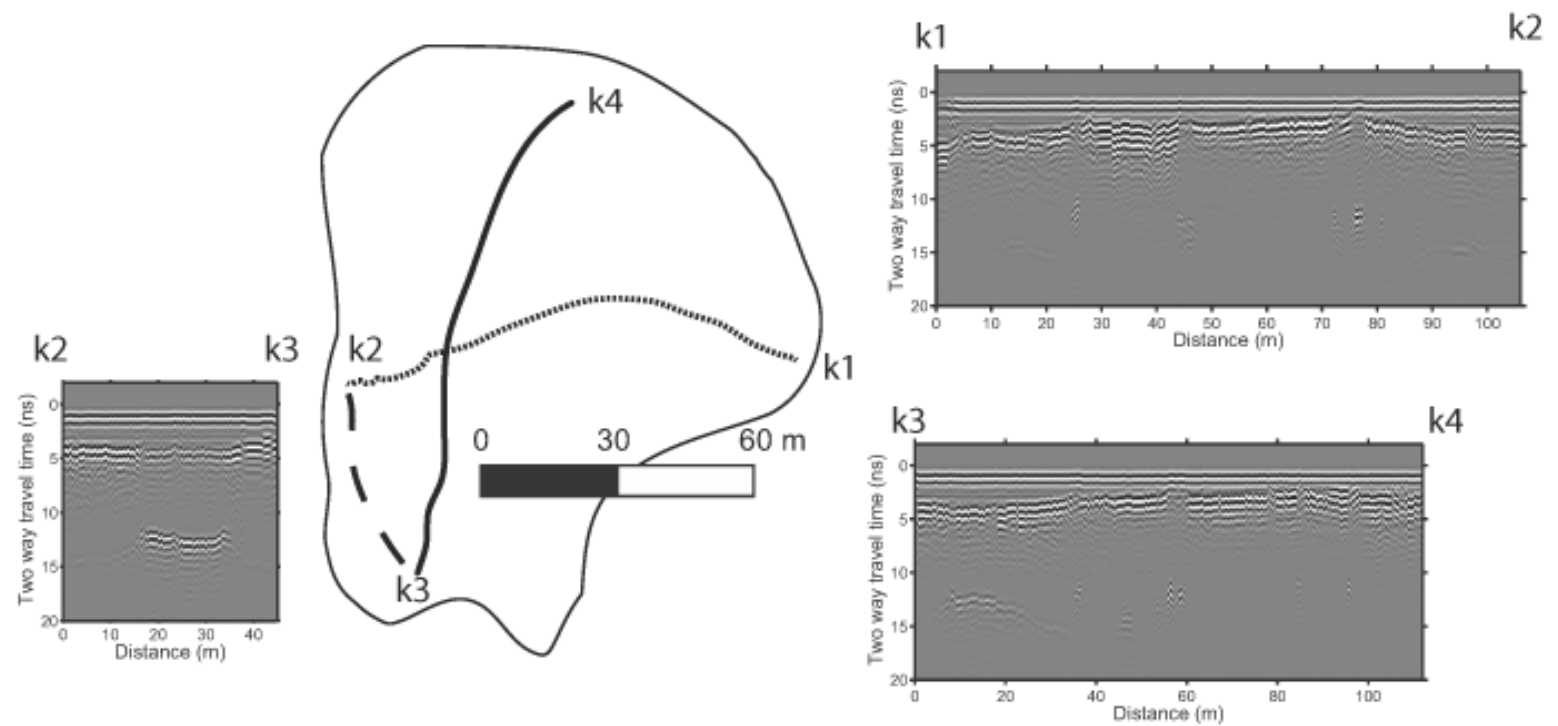

Fig. 4. $1 \mathrm{GHz}$ GPR profiles acquired at Killarney Lake. Variable overflow water was noticed at the snow-ice interface. The intensity of the snow-ice reflection is variable. 

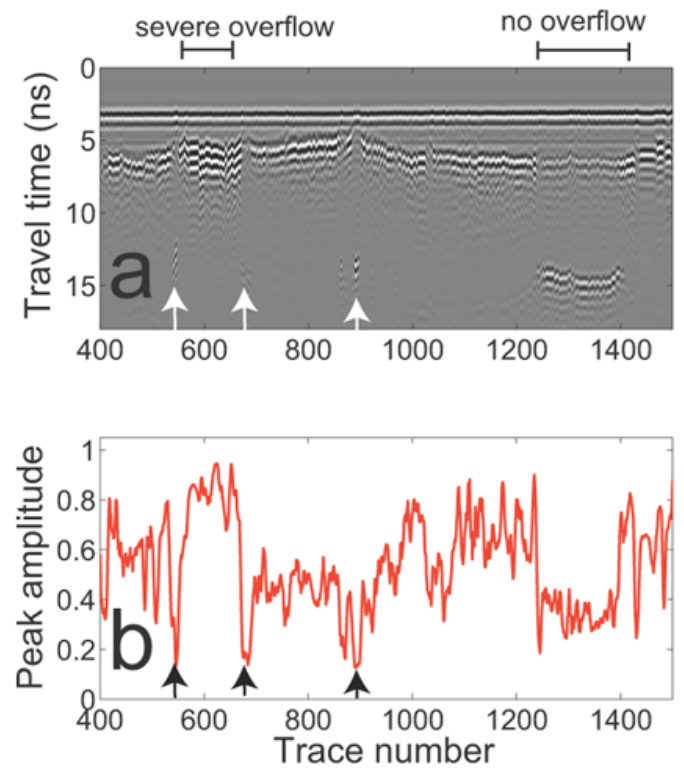

Fig. 5. Detailed analysis of the snow-ice reflections at Killarney lake. (a) shows the GPR data acquired all over the lake whereas (b) shows the intensity of the reflection measured using the peak amplitude of the Fast Fourier Transform. The magnitude of the intensity varies with space and is controlled by the presence of overflow water. White arrows indicate points in which the GPR profile crossed ski paths (see discussion in text).

Table 1. Parameters used in the synthetic model.

\begin{tabular}{lr}
\hline medium & $\varepsilon$ \\
\hline water & 80 \\
ice & 3.2 \\
dry snow & 1.68 \\
wet snow $\theta_{\mathrm{W}}=5 \%, \theta_{\mathrm{a}}=40 \%$ & 6 \\
slush I $\theta_{\mathrm{w}}=10 \%, \theta_{\mathrm{a}}=15 \%$ & 11 \\
slush II $\theta_{\mathrm{W}}=30 \%, \theta_{\mathrm{a}}=10 \%$ & 26 \\
slush III $\theta_{\mathrm{w}}=45 \%, \theta_{\mathrm{a}}=5 \%$ & 38 \\
\hline
\end{tabular}

simple modeling, we can argue that slush with $\theta_{\mathrm{w}}>10 \%$ is necessary for obscuring the the ice-water reflection and that the highest data points in Figs. 5 and 6 have $\theta_{\mathrm{w}}>30 \%$.

\subsection{Radar characteristics of ice covered lakes}

Arcone et al. (1997) studied lakes on the Alaskan North Slope and demonstrated that $X$ and $C$ band radar can be used to profile lake ice thickness. The study of Arcone et al. (1997) was undertaken with dry snow-ice conditions. In dry conditions, it is possible to continuously profile lake-ice (Arcone et al., 1997); in wet conditions, instead, the presence of liquid water beneath the snowpack strongly affects the radar response. The intensity of the GPR reflection is much higher in the case of a wet snow-ice interface. The occurrence of

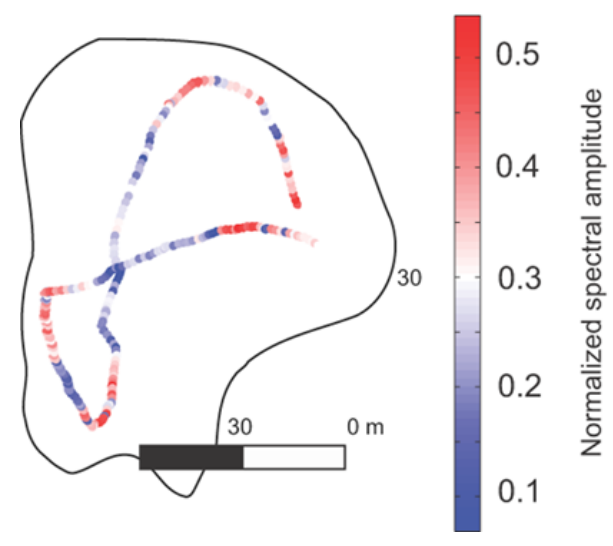

Fig. 6. Spatial variability of base-of-the-snowpack radar reflectivity at Killarney Lake on 21 March 2011. Spectral amplitudes are corrected for geometric divergence within the snow. High amplitudes represent hotspots of high overflow.

radar returns from the base of the lake ice strongly depends on the presence or absence of overflow slush. The presence of slush attenuates the radar signal. This is because overflow moisturizes the snowpack and increases its dielectric permittivity (Fig. 6).

From our GPR profiles we can also notice the potent insulating effect of the snow cover. In some locations our GPR surveys intersected established ski paths (e.g., Fig. $2 \mathrm{~b}$ and arrows in Fig. 5). Snow on substantially compacted, established ski-paths is very different than pristine snow: it is thinner, denser and has a much higher thermal conductivity than the pristine sub arctic snow composed prevalently by coarse, low-density, depth hoar layers (Sturm and Johnson, 1992; Sturm et al., 1997; Zhang, 1996). In a pristine subArctic snowpack, the depth hoar fraction can be over $50 \%$ Sturm and Johnson (1992). The effective thermal conductivity of the depth-hoar is $0.063 \mathrm{~W} \mathrm{~m}^{-1} \mathrm{~K}^{-1}$, about one fifth to one twentieth the value of high density packed slabs. It is therefore likely that the thicker ice, frozen to the bottom in Figure $2 b$ is due to the smaller insulating effect of the packed snow cover. At Killarney Lake the presence of moderately compacted ski-trails, freshly established on the day before our GPR survey, caused water overflow to freeze overnight. These areas are noticeable in the GPR data by the sporadic appearing of the ice-water reflector when the GPR profile intersected the ski trails (White arrows in Fig. 5).

Our results have implications on the use of Synthetic Aperture Radar (SAR) imagery for the study of Arctic lakes. SAR techniques are known to be an effective way to characterize Arctic lake ice (Jeffries et al., 1998). Space-borne SAR studies investigating seasonal lake ice characteristics in high latitude lakes indicate that snow characteristics may be an important factor for radar backscatter during different parts of the season. For example, Duguay et al. (2002) suggest that an observed decrease in Radarsat-1 backscatter for sub-Arctic 


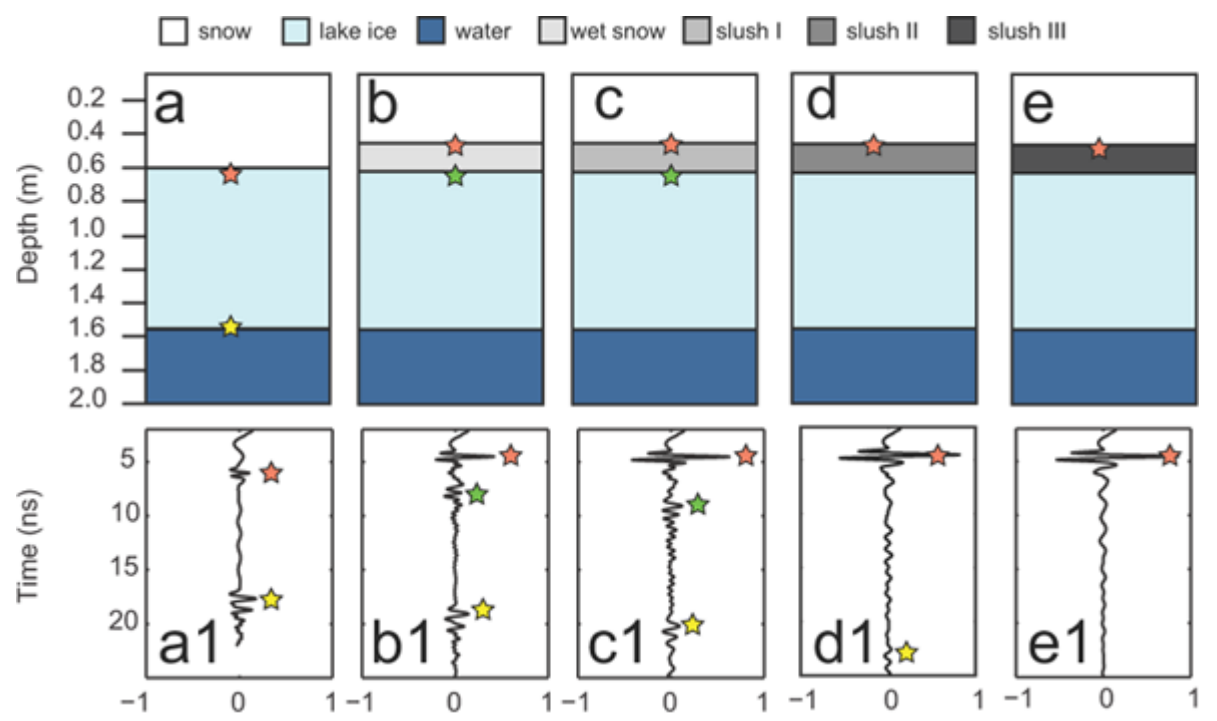

Fig. 7. Synthetic model of a GPR survey over lake ice. Model configurations are provided in panel (a) to (e). Simulated GPR trace are shown in panel from (a) to (e1). (a), (a1) Dry case with no water between snow and ice. (b), (b1) Same as (a) with a $18 \mathrm{~cm}$ layer of wet snow (properties in Table 1); (c), (c1) same as (a) with a $18 \mathrm{~cm}$ layer of slush I (properties in Table 1); (d), (d1) same as (a) with a $18 \mathrm{~cm}$ layer of slush II (properties in Table 1); (e), (e1) same as (a) with a $18 \mathrm{~cm}$ layer of slush III (properties in Table 1).

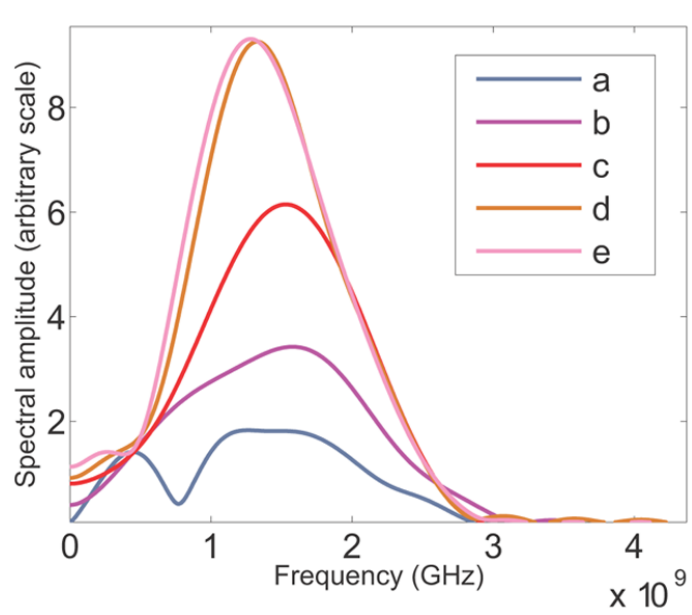

Fig. 8. Spectral amplitude of the simulated GPR reflections from different snow-ice interfaces (Table 1 for parameters). (a) Dry snow ice interface, (b) wet-snow, (c) slush I, (d) slush II, (e) slush III.

lake ice during spring is related to lake ice decay, ponding on the lake ice surfaces, and also wet snow. The presence of basal slush and snow-ice (granular ice formed by refreezing overflows) is commonly reported in SAR and lake-ice studies (Adams and Roulet, 1980; Duguay and Lafleur, 2003; Nolan et al., 2003; Walter et al., 2008). Nolan et al. (2003) suggested that snow-ice formation is an occasional, localized phenomenon detectable as cracks from SAR imagery of a large Siberian lake. In both Ace Lake and Killarney Lake, the GPR profile shows that basal-slush (and subsequent snow-ice formation) is widespread on the lake. Walter et al. (2008) rec- ognized the potential confounding role of slush in SAR studies of methane bubbles trapped in lake ice and suggested that SAR studies focusing on methane ebullition might perform best in early winter, before large snowfalls generate overflow and snow-ice. Our results show that presence or absence of slush is a primary control on the radar returns from the snowice and ice-water interfaces. Future work should focus on quantitative studies of overflow slush as well as assessment of spatial and temporal distribution of overflows.

\subsection{Changing lakes in a changing climate}

Several studies indicate that Arctic lakes are important components of the climate system (Brown et al., 2010; Latifovic and Pouliot, 2007) and are changing rapidly with current climate shifts in northern high latitudes. Climate warming will have a profound impact on the thermal characteristics of lakes, ice, and snow cover (Arp et al., 2010). Observations from the Arctic Coastal Plain indicate that lake ice regimes are shifting from grounded ice towards floating ice lakes due to thinner ice cover (Arp et al., 2011, 2012). Thinning of ice cover in Subarctic and Arctic lakes, in combination with a projected increase of winter precipitation for many regions (Arctic Monitoring Assessment Programme, 2011) may increase the occurrence of overflow slush. In this evolving situation GPR will be a useful tool to monitor lake ice dynamics, spatially and temporally. 


\section{Conclusions}

Ice-covered shallow lakes and ponds are ubiquitous during the winter in the Arctic. Northern communities use these lakes for recreation and subsistence. Safe access to the lakes is guaranteed when the ice is thick enough and there is no liquid water beneath the snowpack. Radar systems are typically used to measure ice thickness, but no method has yet been proposed to detect and spatially characterize the presence of subsnow overflow slush. In this study we have shown that a lightweight, user-friendly, commercially available $1 \mathrm{GHz}$ Ground Penetrating Radar system is able to detect presence and magnitude of overflow. The presence of subsnow overflow slush was a significant problem in profiling ice thickness. When overflow was present, no reflection from the ice base was retrievable. Our results suggest that future GPR surveys devoted to ice thickness measurements of Northern Lakes should not be conducted while slush is on the ice (e.g., just after a significant snowfall). A similar GPR, mounted on remotely controlled, unmanned small aircrafts can provide a safe way to detect extent and magnitude of overflow slush over frozen freshwater bodies.

Acknowledgements. The project described in this publication was supported by the Alaska Climate Science Center, funded by Cooperative Agreement Number G10AC00588 from the United States Geological Survey. Its contents are solely the responsibility of the authors and do not necessarily represent the official views of USGS. GG was supported by NASA grant NNX08AJ37G and NSF ARC-1107607. We thank S. Fowell, E. C. Pettit and C. Wyatt of the Department of Geology and Geophysics at the University of Alaska Fairbanks for their availability letting us borrow their GPR system. A. Parsekian provided an informal review which improved the manuscript. C. Arp is also acknowledged for valuable help in the field. AG thanks L. Hinzman, S. Rupp, M. Sturm and S. Filhol for support, encouragement and inspirational discussions about snow and ice. N. Bauer provided useful edits. Careful and constructive reviews from A. Heilig and S. H. Hamran greatly improved the manuscript.

Edited by: J. O. Hagen

\section{References}

Adams, W. P. and Roulet N. T.: Illustration of the roles of snow in the evolution of the winter cover of a lake, Arctic, 33, 100-116, 1980.

Adolphs, U.: Ice thickness variability, isostatic balance and potential for snow ice formation on ice floes in the south polar Pacific Ocean, J. Geophys. Res., 103, 24675-24691, doi:10.1029/98JC02414, 1998.

AMAP: Snow, Water, Ice and Permafrost in the Arctic (SWIPA): Climate Change and the Cryosphere, Arctic Monitoring and Assessment Programme (AMAP), Oslo, Norway, 538 pp., 2011.
Arcone, S. A. and Delaney, A. J.: Airborne river-ice thickness profiling with helicopter-borne UHF short-pulse radar, J. Glaciol., 33, 330-340, 1987.

Arcone, S. A., Yankelun, N. E., and Chacho, E. F.: Reflection profiling of Arctic lake ice using microwave FM-CW radar, Trans. Remote Sens., 35, 436-443, 1997.

Arp, C. D. and Jones, B. M.: Geography of Alaska lake districts: Identification, description, and analysis of lake-rich regions of a diverse and dynamic state, US Geol. Surv. Sci. Invest. Rep., 2008-5215, 40 pp., 2009.

Arp, C. D., Jones, B. M., Whitman, M., Larsen, A., and Urban, F.: Lake Temperature and Ice Cover Regimes in the Alaskan Subarctic and Arctic: Integrated Monitoring, Remote Sensing and Modeling, JAWRA, J. Am. Water Resour. As., 46, 777-791, 2010.

Arp, C. D., Jones, B. M., Urban, F. E., and Grosse, G.: Hydrogeomorphic processes of thermokarst lakes with grounded-ice and floating-ice regimes on the Arctic coastal plain, Alaska, Hydrol. Processes., 25, 2422-2438. doi:10.1002/hyp.8019, 2011.

Arp, C. D., Jones, B. M., Lu, Z., and Whitman, M. S.: Shifting balance of thermokarst lake ice regimes across the Arctic Coastal Plain of northern Alaska, Geophys. Res. Lett., 39, L16503, doi:10.1029/2012GL052518, 2012.

Bradford, J. H., Dickins, D. F., and Brandvik, P. J.: Assessing the potential to detect oil spills in and under snow using airborne ground-penetrating radar, Geophys., 75, 1-12, 2009a.

Bradford, J. H., Harper, J. T., and Brown, J.: Complex dielectric permittivity measurements from ground-penetrating radar data to estimate snow liquid water content in the pendular regime, Water Resour. Res., 45, W08403, doi:10.1029/2008WR007341, 2009b.

Brown, L. C. and Duguay, C. R.: The response and role of ice cover in lake-climate interactions, Prog. Phys. Geog., 34, 671704, 2010.

Duguay, C. R. and Lafleur, P. M.: Determining depth and ice thickness of shallow sub-Arctic lakes using space-borne optical and SAR data, Int. J. Remote Sens., 24, 475-489, 2003.

Duguay, C. R., Pultz, T. J., Lafleur, P. M., and Drai, D.: RADARSAT backscatter characteristics of ice growing on shallow sub-Arctic lakes, Churchill, Manitoba, Canada, Hydrol. Processes, 16, 1631-1644, 2002.

Gusmeroli, A., Clark, R. A., Murray, T., Booth, A. D., Barrett, B. E., and Kulessa, B.: Seismic wave attenuation in the uppermost glacier ice of Storglaciaren, J. Glaciol., 54, 939-942. 2010.

Gusmeroli, A., Jansson, P., Pettersson, R., and Murray, T.: Twenty years of cold surface layer thinning at Storglaciären, sub-Arctic Sweden, 1989-2009, J. Glaciol., 58, 207, doi:10.3189/2012JoG11J018, 2012.

Heilig, A., Eisen, O., and Schneebeli, M.: Temporal observations of a seasonal snowpack using upward-looking GPR, Hydrol. Processes., 24, 3133-3145, doi:10.1002/hyp.7749, 2010.

Holmgren, J., Sturm, M., Yankeluin, N. E., and Koh, G.: Extensive measurements of snow depth using FM-CW radar, Cold Reg. Sci. Technol., 27, 17-30, 1998.

Irving, J. and Knight, R.: Numerical modeling of groundpenetrating radar in 2-D using MATLAB, Comput. Geosci., 32, 1247-1258, 2006.

Jeffries, M. O., Zhang, T., Frey, K., and Kozlenko, N.: Estimating late-winter heat flow to the atmosphere from the lake-dominated Alaskan North Slope, J. Glaciol., 45, 315-324, 1998. 
Jones, B. M., Grosse, G., Arp, C. D., Jones, M. C., Walter Anthony, K. M., and Romanovsky, V. E.: Modern thermokarst lake dynamics in the continuous permafrost zone, northern Seward Peninsula, Alaska, J. Geophys. Res., 116, G00M03, doi:10.1029/2011JG001666, 2011.

Latifovic, R. and Pouliot, D.: Analysis of climate change impacts on lake ice phenology in Canada using the historical satellite data record, Remote Sens. Environ., 106, 492-507, 2007.

Lepparanta, M. and Kosloff, P.: The Structure and Thickness of Lake Pääjärvi Ice, Geophysica, 36, 233-248, 2000.

Liston, G. E. and Hall, D. K.: An energy-balance model of lake-ice evolution, J. Glaciol., 41, 373-382, 1995.

Macguth, H., Eisen, O., Paul, F., and Hoelzle, M.: Strong spatial variability of snow accumulation observed with helicopter-borne GPR on two adjacent Alpine glaciers, Geophys. Res. Lett., 33, L13503, doi:10.1029/2006GL026576, 2006.

Marshall, H. P., Koh, G., and Forster, R. R.: Estimating alpine snowpack properties using FMCW radar, Ann. Glaciol., 40, 157-162, 2005.

Mitterer, C., Heilig, A., Schweizer, J., and Eisen, O.: Upwardlooking ground penetrating radar for measuring wet-snow properties, Cold Reg. Sci. Technol., 69, 129-138, 2011.

Nolan, M., Liston, G., Prokein, P., Brigham-Grette, J., Sharpton, V. L., and Huntzinger, R.: Analysis of lake ice dynamics and morphology on Lake Elgygytgyn, NE Siberia, using synthetic aperture radar (SAR) and Landsat, J. Geophys. Res., 107, 8162, doi:10.1029/2001JD000934, 2002.

Peters, L. E., Anandakrishnan, S., Alley, R. B., and Voigt, D. E.: Seismic attenuation in glacial ice: A proxy for englacial temperature, J. Geophys. Res., 117, F02008, doi:10.1029/2011JF002201, 2012.

Perla, R.: Real permittivity of snow at $1 \mathrm{MHz}$ and $0^{\circ} \mathrm{C}$, Cold Reg. Sci. Technol., 19, 215-219, 1991.

Robin, G.: Velocity of radio waves in ice by means of a bore-hole interferometric technique, J. Glaciol., 15, 151-158, 1975.
Roth, K., Schulin, R., Fluhler, H., and Attinger, W. : Calibration of time domain reflectometry for water-content measurements using a composite dielectric approach, Wat. Resour. Res., 26, 2267-2273, 1990.

Saloranta, T. M.: Modeling the evolution of snow, snow ice and ice in the Baltic Sea, Tellus, 52A, 93-108, 2000.

Smith, L. C., Sheng, Y., and MacDonald, G. M.: A first pan Arctic assessment of the influence of glaciation, permafrost, topography and peatlands on northern hemisphere lake distribution, Permafrost Periglac., 18, 201-208, doi:10.1002/ppp.581, 2007.

Sturm, M. and Johnson, J.: Thermal conductivity measurements of depth hoar, J. Geophys. Res., 97, 2129-2139, doi:10.1029/91JB02685, 1992

Sturm, M. and Liston, G.: The snow cover on lakes of the Arctic Coastal Plain of Alaska, USA, J. Glaciol., 49, 370-380. 2003.

Sturm, M., Holmgren, J., Konig, M., and Morris, K.: The thermal conductivity of seasonal snow, J. Glaciol., 43, 26-41, 1997.

Tzanis, A.: MATGPR: A freeware MATLAB package for the analysis of common-offset GPR data, Geophys. Res. Abstracts, 8, 09488, http://meetings.copernicus.org/www.cosis.net/ abstracts/EGU06/09488/EGU06-J-09488.pdf, 2006.

Walter, K. M., Engram, M., Duguay, C. R., Jeffries, M. O., and Chapin, F. S.: The Potential Use of Synthetic Aperture Radar for Estimating Methane Ebullition From Arctic Lakes, J. Am. Water Resour. As., 44, 305-315, 2008.

Walter Anthony, K. M., Vas, D., Brosius, L., Chapin III, F. S., Zimov, S. A., and Zhuang, Q.: Estimating methane emissions from northern lakes using ice bubble surveys, Limnol. Oceanogr.Meth., 8, 592-609, 2010.

Zhang, T., Osterkamp, T. E., and Stamnes, K.: Influence of the depth hoard layer of the seasonal snow cover on the ground thermal regime, Water Resour. Res., 32, 2075-2086, 1996. 